\title{
USE OF ETHYL VINYL ETHER FOR GENERAL AND THORACIC SURGERY*
}

\author{
Doris C. Grosskreutz, M.D * and David A. Davis, M.D. ${ }^{* * *}$
}

ALTHOUGH ethyl vinyl ether was studied and its anaesthetic properties reported in 1930 by Leake and Chen (1), it was not until 1947 that Krantz $(2,3)$ worked extensively with it in ammals and applied it to man Since 1952 investigatoons have been made in several clinics throughout the United States and Canada to ascertain a place for this hybrid compound in modern anaesthetic practice

Chemically ethyl vinyl ether is an asymmetric, unsaturated ether containing an ethyl radical and a vinyl radical, thus offermg properties simi ar to divinyl ether and diethyl ether. It is a clear, colourless liquid with a slightly pungent but<smiles>C=COCC</smiles>

Molecular structure of ethyl vinyl ether

not irntating odour It has a bolling point of $358^{\circ} \mathrm{C}$ with a vapor density of 2.49. Although it tends to polymerize and oxidize to aldehydes in the presence of acid, light, and mossture, if treated with 001 per cent n-phenyl alpha naphthylamine and 3 per cent absolute alcohol it can be stored for a year tightly stoppered in a cool, dark place. It does not form toxic products with soda lime

TABLE I

Physical Properties of Ethyl Vinyl Ether

\begin{tabular}{ll}
\hline \hline Appearance & Colourless, clear \\
Odour & Slightly pungent \\
Bolling point & $358^{\circ} \mathrm{C}$ \\
Specific gravity & 0759 at $20^{\circ} \mathrm{C}$ \\
Molecular weight & 7210 \\
Vapour pressure & $485 \mathrm{~mm}$ at $22^{\circ} \mathrm{C}$ \\
Range of flammability & Lower limit in $\mathrm{O}_{2} \quad 21 \%$ \\
\hline
\end{tabular}

in the presence of heat and thus can be used safely in a closed system. Like the other ethers, it forms explosive mixtures, its lower limit of flammability in oxygen

'Presented at the Annual Meeting, Canadian Anaesthetısts' Society, Mont Tremblant, P.Q, June 18-20, 1956

*Assistant Professor of Anesthesiology, Duke University Hospital and School of Medicine, Durham, North Carolina

* Professor of Anesthesia, University of North Carolina Medical School, Chapel Hill, North Carolina.

Can. Anaes Soc J, vol. 3, no 4, Oct, 1956 
is at 2.1 per cent concentration so that suitable precautions must be taken to prevent ignition (4).

The margin of safety in dogs has been found by Krantz (2) to be slightly greater than diethyl ether and twice as great as divinyl ether, while the potency of ethyl vinyl ether for induction almost equals that of divinyl ether (3). Dornette and co-workers (5) reported no demonstrable pathological changes in the liver, kidney, lung, and heart: after repeated administrations to dogs, while in a similar series using divinyl ether Orth (6) found considerable central necrosis of the liver. Morch (7) saw depression both of respiration and blood pressure in deep planes but this was much less marked than that caused at similar levels with divinyl and diethyl ether.

\section{Clinical Application}

Ethyl vinyl ether has been employed in our clinic during the past year on 239 patients for a wide range of surgical procedures. They were unselected, ranging in age from 7 days to 82 years and in weight from 6 to 220 pounds. Although 78 per cent were judged to be in a good physical state, it has been employed in patients with diabetes, bronchiectasis, tuberculosis, thyrotoxicosis,

TABLE II

AgES

\begin{tabular}{cccc}
\hline Ages & No of patients & Ages & No of patients \\
\hline $0-1$ & 13 & $40-49$ & 35 \\
$1-9$ & 64 & $50-59$ & 28 \\
$10-19$ & 31 & $60-69$ & 8 \\
$20-29$ & 33 & $70-79$ & 2 \\
$30-39$ & 25 & $80+$ & 1 \\
\hline
\end{tabular}

dıminished liver function, cardiac arrhythmias, hypertension, and pyelonephritıs. The surgical procedures carried out successfully under ethyl vinyl ether covered all types from simple myrmgotomies and closed reductions to pulmonary resections and mitral valvulotomies, and lasted from 10 minutes to $7 \frac{1}{2}$ hours. This anaesthetic agent has been administered by the open drop, semi-closed with nitrous oxide or ethylene, non-rebreathing, and closed carbon dioxide absorption techniques for both induction and maintenance.

Ethyl vinyl ether permitted a rapid unduction in $1 \frac{1 \% 2}{2}$ to 4 minutes by both the open drop and semi-closed techniques. Although the odour annoyed operating room personnel it was readily acceptable to the patient. Being less of an irritant to the respiratory tract than divinyl ether, the incidence of breath-holding and laryngospasm was low. Too rapid administration, however, could cause coughing but this was easily controlled and never paroxysmal with resultant cyanosis as often seen with diethyl ether.

Open drop ethyl vinyl ether proved to be a satisfactory method of analgesia in burn dressings, simple closed reductions, and obstetrical cases, allowing as steady 
TABLE III

Types of Procedures

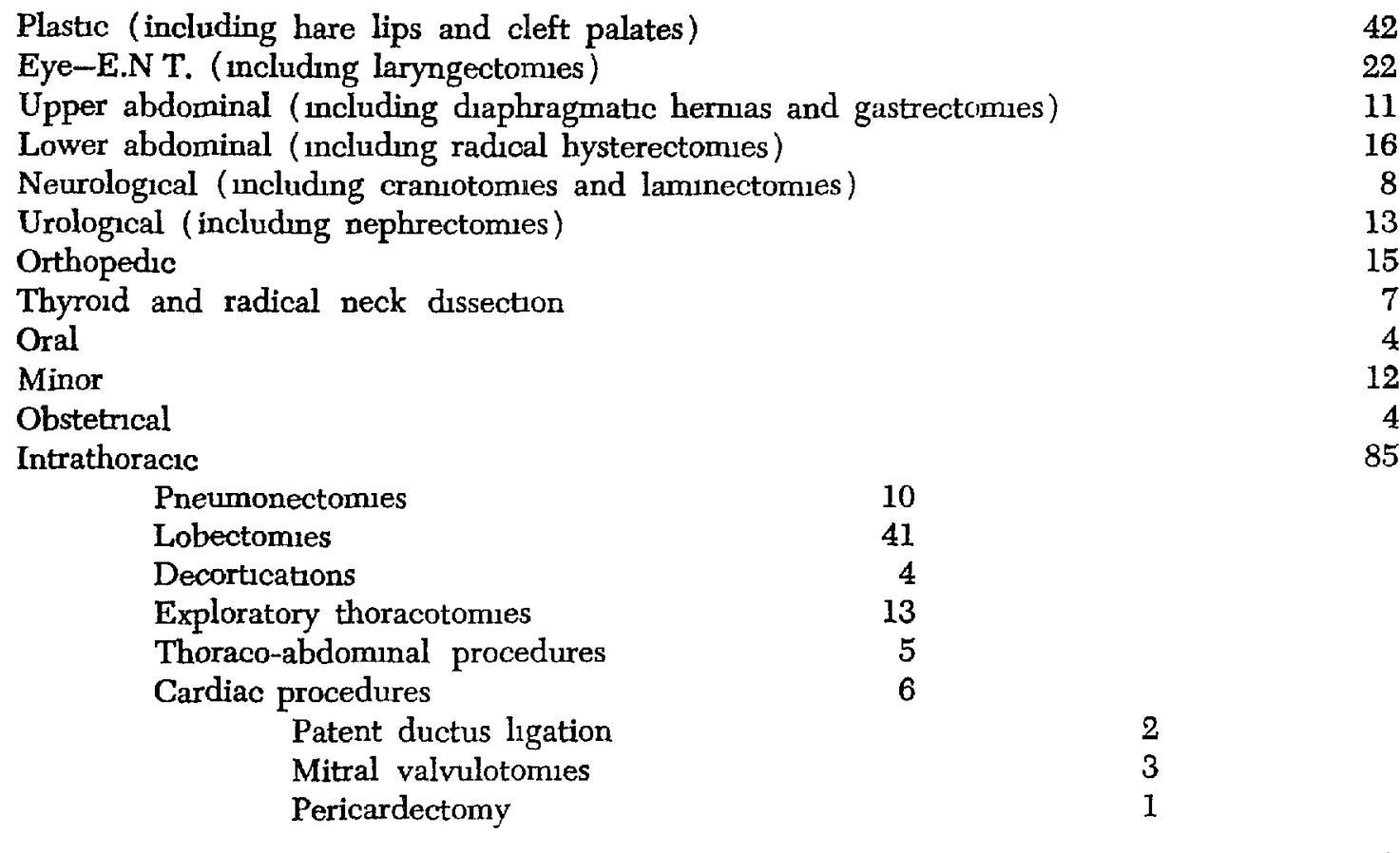

a maintenance of this stage as is obtained with divinyl ether. The intubations performed under ethyl vinyl ether alone were limited to the younger age group under 10 years as the relaxation of the jaw was poor and the cords remained active so that considerable skill was required for an atraumatic intubation Although unsatisfactory for oral intubation without a muscle relaxant, it proved adequate for blind nasal intubation. Without a previous topical application of a local anaesthetic agent to the larynx and trachea, insertion of the tube caused bucking and bronchiolar spasms which were not, however, as severe as those seen in equally light planes with thiopental or cyclopiopane The major part of these could be subdued within 1 to 3 minutes by deepening of the anaesthetic plane. Excessive salivation previously reported (8) was not noted in this series but all patients had received either scopolamine or atropine before induction Vomiting on induction did not occur even in the emergency patient owing to minimal irritative properties although this was not true on emergence Patients with known full stomachs, however, were not given ethyl vnnyl ether.

Maintenance of anaesthesia by the various techniques mentioned above was satisfactory in all cases not requiring deep planes of anaesthesia. Depth could be rapidly altered in 30 to 90 seconds as demonstrated by changes in the electroencephalographic tracings Muscle relaxation, however, was unrehable and although abdominal relaxation was adequate for inthaperitoneal procedures in children under 5 years, succinylcholine was required for the opening and closing of the peritoneal cavity in the majority of abdominal cases.

Ethyl vinyl ether was administered to 85 patients undergoing various intrathoracic procedures including cardiac surgery and repair of tracheo-esophageal 
TABLE IV

Duration

\begin{tabular}{cccc}
\hline Duration & No of cases & Duration & No. of cases \\
\hline$-1 / 2 \mathrm{hr}$ & 15 & $3-4 \mathrm{hrs}$ & 30 \\
$1 / 2 \mathrm{hr}$ & 44 & $4-5 \mathrm{hrs}$ & 28 \\
$1-2 \mathrm{hrs}$. & 61 & $5-6 \mathrm{hrs}$ & 17 \\
$2-3 \mathrm{hrs}$. & 39 & $6+\mathrm{hrs}$ & 5 \\
\hline
\end{tabular}

TABLE V

Technique of ADMINISTRATION

\begin{tabular}{lc}
\hline \multicolumn{1}{c}{ Type } & No of patients \\
\hline Open drop analgesia & 12 \\
Open drop anesthesia & 39 \\
Semi-closed with $\mathrm{N}_{2} \mathrm{O}$ or $\mathrm{C}_{2} \mathrm{H}_{4}$ & 140 \\
Closed $\mathrm{CO}_{2}$ absorption & 32 \\
Non-rebreathing & 38 \\
Endotracheal & 132 \\
\hline
\end{tabular}

fistulae. After the usual premedicaton of Nembutal $($, Demerol $\AA$, and scopolamine, induction and intubation were accomplished under thopental, succinylcholine, and topical Pontocameß in all but the infants on whom only inhalation agents were employed. For maintenance ethyl vinyl ether was started immediately after loss of the eyelash reflex, mainly by the semi-closed technique with nitrous oxide or ethylene for the adults and non-rebreathing for infants. Assisted or controlled respiration was used as the situation demanded and a mechanical ventilator was employed in seven of these cases

Patients were maintained at a level light enough to make it possible for them to move their hands on occasion or wrinkle their brows but no bucking occurred unless carinal stimulation was severe Electroencephalographic tracing at this stage corresponded to level 2 of diethyl ether anaesthesia.

The most impressive observation was the smoothness and quietness of respiration in the light plane of anaesthesia maintamed. As deeper planes were attained there was a gradual decrease in amplitude but rate did not appeár to be affected. Adequate inflation of the lung could be accomplished by relatively low positive pressure and an increase in compliance of the lung or a decrease in aurway resistance was felt as the respirations were assisted. Laboratory confirmation of this possibility is underway and will constitute a future report. Respiration could be controlled readily withn a two-minute period without increasing the anaesthetic concentration and similarly, spontaneous respiration was resumed quickly and smoothly without the bucking on the endotracheal tube which is often seen following the lightening of the plane of anaesthesia when cyclopropane is used to control respiration. 
The mechanical ventilator could be introduced readily into the system owing to this ease of controlling respiration and of maintaining such control with minimal amounts of ethyl vinyl ether vapor Patients would remain on control even though they occasionally moved an extremity One case was managed on the Jefferson ventulator with semi-closed nitrous oxide and ethyl vinyl ether using $150 \mathrm{cc}$. over a $6 \%$ hour period, the patient responded withn 5 minutes of discontnumg the anaesthesia

The rapid shift of the depth of anaesthesia allowed desurable control with the patient coughing at the end of the procedure No increase in bronchial secretions was noted although bronchiolar spasms developed in 14 per cent of the cases, mainly because of pre-existing secretions or inadequate topical anaesthesia. Sixty per cent of these responded to suction and a slight deepening of the plane, 40 per cent had to be given additional medication of ammophylline or succinylcholine because in these patients deepening was followed by hypotension.

While the effect on respuration was ethyl vinyl ether's greatest asset, the effect on blood pressure was its greatest detriment. The blood pressure remained relatuvely stable in 76.4 per cent of the cases, increased from 20 to $60 \mathrm{~mm}$. $\mathbf{H g}$.

\section{TABLE VI}

Changes in Blood Pressume and Pulse Rate

Blood Pressure

Increased 20-60 mm. $\mathrm{Hg}$

General Surgical Senies

Thoracic Surgical Series

$12 \%$

$10 \%$

Decreased $20-80 \mathrm{~mm}$. $\mathrm{Hg}$

General Surgical Senes

Thoracic Surgical Senes

Due to deepening

Due to turning

$142 \%$

$16.4 \%$

Due to $\mathrm{rab}$ resection

$48 \%$

Pulse

Increased $20-60 \mathrm{~b}$ p m.

Decreased 20-40 b.p.m.

Pulse Pressure

Decreased $20-40 \mathrm{~mm} \mathrm{Hg}$

in 11.3 per cent, and decreased from 20 to $80 \mathrm{~mm}$. $\mathrm{Hg}$. in 12.6 per cent. The increase in pressure seemed to be associated with severe surgical stimulation under light anaesthesia and could be reduced by deepening the plane. In one case carbon dioxide accumulation was definitely incriminated.

Hypotension, for the most part, developed gradually in prolonged surgical cases over a 3- to 5-hour period accompanied by an unchanged pulse rate. In the thoracic series sudden drops of pressure of 20 to $40 \mathrm{~mm}$. $\mathrm{Hg}$. were noted in 16.4 per cent of the cases after the patient was turned into the lateral position, with a spontaneous return to pre-induction levels within 5 minutes in all cases 


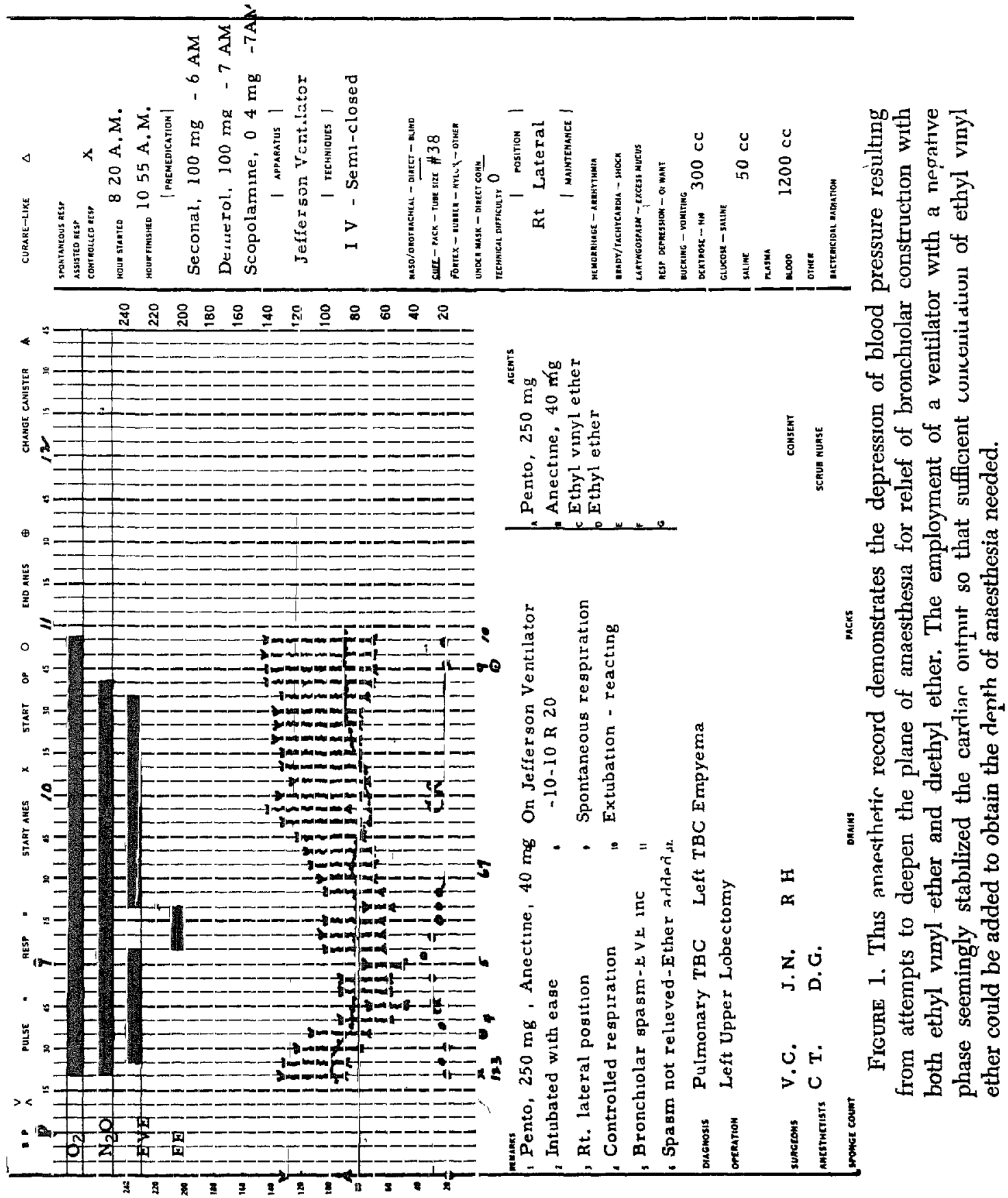


but one. This patient had a hydrothorax and returned to normal only after the pleura was opened. In 4.8 per cent of cases there were severe drops of pressure of 50 to $80 \mathrm{~mm}$. $\mathrm{Hg}$. on stripping the rib and opening the pleura; this was remedied by interruption of surgery and a lightening of the anaesthetic plane.

Hypotension of 30 to $60 \mathrm{~mm}$. Hg. developed on rapid deepening of the anaesthesia in 14.2 per cent; this responded immediately to washing out the excess ethyl vinyl ether. One patient's pressure decreased from $140 / 80$ to $80 / 40$ in 10 minutes with rapid ethyl vinyl ether administration by the closed technique but returned to $140 / 100$ in 10 minutes after this agent was discontinued and high flow oxygen started. Another patient of poor physical status (Fig. 1) could not tolerate the depth of anaesthesia from diethyl ether or from ethyl vinyl ether necessary to control her bronchiolar spasms. When supplied with a negative phase to her respiration by means of the mechanical ventilator, however, her cardiac output seemed to be kept adequate and enough ethyl vinyl ether could be administered to relax the constriction of the lower respiratory tract.

The various autonomic reflexes, such as the hilar reflexes, remained active in the light planes, causing sudden hypotensive periods, but could be obtunded by adequate doses of atropine. Moreover, patients appeared more sensitive to blood loss, developing hypotension from relatively small amounts of haemorrhage and requiring meticulous attention to adequate bløod replacement. Pre-induction hypertension was not aggravated, but the presence of hypotension to us represented a contraindication to the use of this agent.

The pulse pressure showed a decrease of 20 to $40 \mathrm{~mm}$. Hg in 12.9 per cent of the cases. The pulse rate remained unchanged in 70 per cent with a decrease of 20 to 40 beats per minute in 9 per cent and an increase of $20-60$ beats per minute in 21 per cent. This increase was seen especially in the younger age group. No arrhythmias were noted by clinical observation to develop during maintenance, while preoperative sinus tachycardia and ventricular extrasystoles were not worsened. The major disturbance found on serial electrocardiographic tracings taken during maintenance with ethyl vinyl ether revealed a descent of the pace maker to the $\mathrm{A}-\mathrm{V}$ node which was reversed following the termination of the anaesthesia Two patients showed frequent aur.cular premature beats and one developed a pulsus bigeminus, all disappeared when the anaesthesia was lightened. Four mitral valvulotomies were performed with no arrhythmias developing during manipulation of the valve. No disturbance was seen by its use in digitalized patients or in a patient with a bundle branch block resulting from a previous myocardial infarction. The arrhythmias which developed under cyclopropane were not seen after changing to ethyl vinyl ether.

Ethyl vinyl ether proved itself a satisfactory agent in 94 per cent of these cases. Clonus of the legs was noted once and mild twitchings in two other cases, response followed a lightening of the anaesthesia and assisted respiration No generalized convulsions developed, probably owing to the meticulous attention given to adequate oxygenation and prevention of hypercarbia.

Recovery was rapid, with over 50 per cent of the patients awake and moving on the table, the remainder responding within 30-45 minutes. Vomiting did occur about as frequently as following other inhalation agents but was not 
prolonged. There were no deaths during surgery and only three in the postoperative period, one from septicaemia, one from coronary thrombosis on the fifth day, and one from pulmonary embolism on the fourth day.

\section{Discussion}

As expected from the chemical structure, ethyl vinyl ether possesses properties of both the vinyl and the ethyl radicals. Its volatility, near that of diethyl ether, allows its effective use by the open drop technique yet prevents frosting of the mask and the sudden dangerously high concentration possible with divinyl ether. Its analgesic properties are useful in burn dressings, minor surgical procedures, and obstetrics where anaesthesia is neither desired nor required. Its potency allows a much more rapid induction, quicker emergence, and more facile changes of anaesthetic depth than are accomplished by the use of diethyl ether. It can be administered smoothly by all the modern techniques employed today over a wide range of ages (9) and for relatively long periods of time. Adequate oxygenation with the elimination of carbon dioxide prevents the convulsive tendency inherent in the vinyl radical. This radical when combined with the ethyl radical seems to lose its toxic effect on the liver and kidney as demonstrated by the work of Dornette $(5,10)$ and Sadove (11).

The poor relaxation developing under ethyl vinyl ether permits orotracheal intubation to be accomplished in only the very young or very weak without the use of a muscle relaxant although it provides adequate conditions for blind nasotracheal intubations. Intra-abdominal procedures cannot be performed with success in a safe plane of anaesthesia as deepening anaesthesia for adequate relaxation will often cause profound hypotension. Adding succinylcholine for the opening and the closing of the peritoneum remedies this problem.

Respirations are well maintained but without the increase in rate often seen in children under diethyl ether. The minimal irritation it causes to the respiratory tract avoids the breath-holding and laryngospasm of too rapid administration of diethyl ether. It can be used in the asthmatic patient, although some severe bronchiolar spasms could not be resolved without causing the hypotension attendant on the deeper planes of ana esthesia with this agent.

This hypotensive effect is the drug's greatest deleterious reacton. If deep planes are avoided, this effect is not troublesome and procedures not requiring relaxation can be managed for many hours with satisfaction and safety. The changes in the electrocardiogram seen during the procedures are benign and mainly limited to a development of nodal rhythm which is no more marzed than that developing in similar planes of ether anaesthesia.

The use of ethyl vinyl ether in thoracic surgery has proven to be satisfactory in the majority of cases. The lack of irritative properties to the tracheo-bronchial tree and great potency allow a rapid and smooth change of level of anaesthesia to meet the demands of surgery. The patient can be carried in very light planes without a tendency to react on the endotracheal tube and without exaggerated movements of the diaphragm and mediastinum. The action of the topical agent applied to the larynx must, of course, be considered here in juclging this tolerance that develops. Controlled respiration is accomplished with ease without deepen- 
ing the patient's level and spontaneous respiration can be re-instituted smoothly without any disturbance of the field of operation. The ease of inflation is quite noticeable and although not all broncholar spasms can be controlled at a level of anaesthesia not mitiating hypotension, the relaxation of the bronchiolar muscles is as satisfactory as with diethyl ether. The greatest disadvantage found in this thoracic series is, again, the instability of blood pressure as hypotension can develop on turning the patient as well as on stripping the rib. It is indeed difficult to evaluate the hypotension which develops in these cases. here a situation exists where there is concomitant blood loss and severe surgical trauma in patients of poor physical state usually having an inadequate total blood volume. But it seems probable that this agent has a depressant effect on the peripheral vascular system with some direct cardiac action resulting in decreased heart force. Although the pressure returns to control levels in 5 to 10 minutes without medication, the drop in pressure is highly undesirable especially in patients with coronary insufficiency Mechanisms compensating for blood loss are depressed and blood replacement must be metsculous. The relative stability of the conductive system of the heart under ethyl vinyl ether and the ease of mantaining light planes make the drug attractive for cardiac surgery. The rapid emergence with early return of protective reflexes and consciousness is valuable in these thoracic procedures The flammability, however, deters one from the use of the cautery that often is desirable. Postoperatıve morbidity and mortality compare very favourably with those for diethyl ether.

Although this drug is not the answer to our search for the ideal anaesthetic agent, it has qualities which make it useful if its limitations are respected. Employing it for procedures that require only analgesia or first plane anaesthesia and avolding those requiring relaxation, one has avallable an agent that has desurable controllability and rapidity. Addition of muscle relaxants makes unnecessary the high concentrations of this agent which can result in an unstable peripheral curculatory system With strict adherence to the principles of good anaesthetic management this drug proves valuable particularly in the management of intrathoracic procedures.

\section{SUMMARY}

1 Ethyl vinyl ether is a useful anaesthetic drug in all ages and for all operative procedures not requiring muscle relaxation or the use of the cautery

2. It is an adequate and safe analgesic agent by the open drop technique or as an adjunct to nitrous oxide and ethylene.

3 It can be employed in the non-rebreathing, semi-closed, or closed carbon dioxide absorption techniques.

4 Its advantages are rapid induction, emergence, and shift of level of anaesthesia.

5. Its disadvantages are hypotension in the deeper planes of anaesthesia and lack of rehability of muscle relaxation.

6. It has proven to be a satisfactory agent for thoracic procedures if one is very careful to prevent the hypotension which may develop. 


\section{ACKNOWLEDGMENT}

The authors wish to express therr appreciation to Dr. A. H. Neeley and the Ohıo Chemical Company for furnushing the ethyl vinyl ether "Vinamar" used in this study

\section{RÉSUNÉ}

L'éther éthyl vinylique est un éther asymétrique non saturé contenant un radical éthyl et un radical vinyl; il possède ainsı des propriétés semblables à l'éther divinylıque et à l'éther diéthylique. C'est un liquide clair, incolore, possédant une odeur légèrement piquante mais non irritante. Son point d'ébullition est à $358^{\circ} \mathrm{C}$ et ses vapeurs ont une densité de 2.49. Bien qu'll are une tendance à se polymerıser et à s'oxider en aldehydes én présence d'acide, de lumière ou de champignons, on peut l'emmagasiner pendant un an lorsque, fermé hermétiquement et conservé dans un endroit frass et à l'abri de la lumière, il a été tratté, au préalable, avec 0.01 pour cent n-phenyl alpha naphthylamine et de l'alcool absolu à 3 pour cent. Avec la chaux sodée, il ne forme pas de produrts toxiques mass il est inflammable. lałlmite inférieure de l'inflammabilité dans l'oxygène étant de 2.1 pour cent

L'éther éthyl vinylque est un médicament utale à tous les âges et pour toutes sortes d'opérations ne réquérant pas de relâchement musculaire ou de cautère. C'est un agent analgésique de toute sécurité soit en goutte à goutte, soit en complément du protoxide d'azote ou de l'éthylène On peut l'employer en circuit semi-ouvert, semi-fermé ou fermé avec absorption du $\mathrm{CO}_{2}$. Ses principaux avantages sont - une induction rapide, un changement rapide de plan d'anesthésie. Ses désavantages sont: dans les plans profonds d'anesthésie, de l'hypotension, ensute une inconstance dans le relấchement musculaire. En chirưrgie thoracique, il s'est avéré un agent satisfaisant, mais il faut être attentif pour prévenir l'hypotension qui peut sinstaller

\section{REFERENCES}

1. Leake, G D \& Chen, M Y The Anesthetıc Properties of Certann Unsaturated Ethers. Proc. Soc. Exper. Biol \& Med 28 151-4 (1930)

2 Krantz, J C, Jr, Carr, C J, Iwamoto, H K \& Saverwald, M J Anesthesia XXIX The Potency and Safety of Certain Anesthetic Ethers Anesthesiology 8 497-499 (Sept 1947).

3 Krantz, J C, Jr, Carr, C J, Musser, R D \& Saverwald, M J Anesthesia XXVIII The Anesthetic Action of Ethyl Vinyl Ether J Pharm \& Exp Therap 89 88-95 (May, 1947)

4 Safety in Hospitals Madison, Wisc Ohıo Chemical and Surgical Equipment Company

5 Dornette, W. H L, Bragman, R D \& Orth, OS Absence of Hepatic Toxicity of Ethyl Vinyl Ether Federation Proc 13. 349 (March, 1954)

6 Orth, O S, Slocum, H C, Stutzman, J W, \& MeEk, W J. Studies of Vinethene as an Anesthetıc Agent Anesthessiology 1 246-260 (1940)

7. Morch, E T, Bergen, M S \& AyeregG, J B. To be published

8 Sadove, M S, Kowalski, L F., Balagat, R. C. \& Kral, Z J Ethyl Vinyl Ether in Dental Anesthesia-A Preliminary Study J Am Dent Assoce (to be uublished).

9. Stater, H M Ethyl Vinyl Ether in Pediatric Anesthesia To be published

10. DonnetTe, W H. L \& ORTh, O S. Clinical and Laboratory Expenence with Ethyl Vinyl Ether. Anesth. \& Analg. 34. 26-34 (Jan.-Feb, 1955).

11. Sadove, M S., Wyant, G. M \& Cle rcher, J. O, Jr Ethyl Vinyl Ether: Pharmacological and Clinucal Evaluation. Anesth. \& Analg 34. 235-240 (July-Aug., 1955) 